Review Article

\title{
Current Understanding on the Role of Standard and Immunoproteasomes in Inflammatory/Immunological Pathways of Multiple Sclerosis
}

\author{
Elena Bellavista, ${ }^{1,2}$ Aurelia Santoro, ${ }^{2}$ Daniela Galimberti, ${ }^{3}$ Cristoforo Comi, \\ Fabio Luciani, ${ }^{5}$ and Michele Mishto ${ }^{6,7}$ \\ ${ }^{1}$ Interdepartmental Center for Studies on Biophysics, Bioinformatics and Biocomplexity "L. Galvani" (CIG), University of Bologna, \\ 40126 Bologna, Italy \\ ${ }^{2}$ Department of Experimental, Diagnostic and Specialty Medicine (DIMES), University of Bologna, 40126 Bologna, Italy \\ ${ }^{3}$ Neurology Unit, Department of Pathophosiology and Transplantation, University of Milan, Centro Dino Ferrari, \\ Fondazione IRCCS Cà Granda, Ospedale Maggiore Policlinico, 20122 Milan, Italy \\ ${ }^{4}$ Interdisciplinary Research Center of Autoimmune Diseases (IRCAD), University of Eastern Piedmont, \\ "Amedeo Avogadro," 28100 Novara, Italy \\ ${ }^{5}$ Inflammation and Infection Research Centre, School of Medical Sciences, University of New South Wales, Sydney, NSW 2052, Australia \\ ${ }^{6}$ Institut für Biochemie, Charité Universitätsmedizin Berlin, 10117 Berlin, Germany \\ ${ }^{7}$ Centro Interdipartimentale di Ricerca sul Cancro "Giorgio Prodi," University of Bologna, 40126 Bologna, Italy
}

Correspondence should be addressed to Michele Mishto; michele.mishto@charite.de

Received 27 September 2013; Accepted 12 November 2013; Published 2 January 2014

Academic Editor: Umberto Dianzani

Copyright (C) 2014 Elena Bellavista et al. This is an open access article distributed under the Creative Commons Attribution License, which permits unrestricted use, distribution, and reproduction in any medium, provided the original work is properly cited.

The ubiquitin-proteasome system is the major intracellular molecular machinery for protein degradation and maintenance of protein homeostasis in most human cells. As ubiquitin-proteasome system plays a critical role in the regulation of the immune system, it might also influence the development and progression of multiple sclerosis (MS). Both ex vivo analyses and animal models suggest that activity and composition of ubiquitin-proteasome system are altered in MS. Proteasome isoforms endowed of immunosubunits may affect the functionality of different cell types such as CD8 ${ }^{+}$and $\mathrm{CD} 4^{+} \mathrm{T}$ cells and B cells as well as neurons during MS development. Furthermore, the study of proteasome-related biomarkers, such as proteasome antibodies and circulating proteasomes, may represent a field of interest in MS. Proteasome inhibitors are already used as treatment for cancer and the recent development of inhibitors selective for immunoproteasome subunits may soon represent novel therapeutic approaches to the different forms of MS. In this review we describe the current knowledge on the potential role of proteasomes in MS and discuss the pro et contra of possible therapies for MS targeting proteasome isoforms.

\section{Multiple Sclerosis and Proteasome Isoforms}

Multiple sclerosis (MS) is a chronic disease of the central nervous system (CNS) characterized by the presence of inflammation, myelin damage, and axonal degeneration. There are two main clinical courses of multiple sclerosis: about $90 \%$ of MS patients experience the relapsing-remitting MS phase (RRMS), characterized by disability episodes followed by a complete or partial recovery. Multifocal lesions are found by magnetic resonance imaging, typically but not exclusively, in the white matter of the optic nerve, brain stem, cerebellum, and spinal cord. Some lesions are enhanced after intravenous administration of gadolinium, indicating breakdown of the blood-brain barrier (BBB) as a result of active inflammation. The majority of RRMS patients enter into a secondary progressive phase (SPMS), characterized by a variable degree of inflammation and a continuous and progressive neurological decline in disability state (with or without superimposed relapses) [1,2]. A minor percentage (10\%) of MS patients shows a primary progressive form of MS 
(PPMS), characterized by progression of neurological disability from onset. Clinically relevant factors differentiating RRMS and PPMS are age at disease onset (a decade later in PPMS) and gender (1:1.3 male/female in PPMS versus $1: 2$ in RRMS) [3]. Although the initial course of RRMS and PPMS is very different, both proceed at remarkably similar rates during the progressive phase. However, it is still an ongoing debate whether the RRMS and the progressive forms of MS are the same disease observed at different stages or whether they are pathogenetically different.

One of the factors characterising MS is the autoimmune response against self-antigens and the immune-mediated demyelination which contribute, at least in part, to the neurological manifestations. Based on scientific evidence, it has been proposed that a predisposing genetic background, in combination with environmental factors such as infection, diet, sun exposure, and smoking, drives the immune system to mount an immune response towards a yet unknown myelin antigen, eventually resulting in myelin disruption [4]. Indeed, genetic associations of HLA class II (HLA-DRB1 $\left.{ }^{*} 15\right)$ and HLA class I (HLA-A* $02,-A^{*} 03$, and $\left.-B^{*} 07\right)$ with MS, as well as the presence of autoreactive $\mathrm{CD} 4^{+}$and $\mathrm{CD} 8^{+} \mathrm{T}$ lymphocytes, together with other inflammatory cells and cytokines in active MS lesions, suggest an autoimmune pathogenesis [5, 6]. Several studies support the view that an immune response in MS subjects starts and is maintained in the periphery, and specifically in the lymphatic system, although the most lethal cytotoxic effect occurs in the brain with oligodendrocytes, neuron loss, and plaque formation (outside-in model) [2]. A competing view argues that the initial malfunction occurs within the CNS, similarly to other neurodegenerative diseases, by cytodegeneration, possibly focused on the oligodendrocyte-myelin complex, and a release of highly antigenic constituents that secondarily promote an autoimmune and inflammatory response in predisposed individuals $[2,7]$.

In the last few years, additional players have emerged in the MS pathogenic cascade, including proteasome and gut microbiota (for the latter see Section 3). The proteasome is the central catalytic unit of the ubiquitin-proteasome system, which plays several crucial functions for cell metabolism (Figure 1). By eliminating obsolete, misfolded, or aberrant proteins, the ubiquitin-proteasome system accomplishes housekeeping functions and maintains cellular homeostasis and the physiological levels of intracellular proteins. It has been demonstrated that proteasome inactivation leads to cellular death by apoptosis or necrosis [8-10]. The central role of ubiquitin-proteasome system in inflammatory responses is supported by evidence of its involvement in the on/off switching of many cellular pathways through the timespecific cleavage of short-life proteins, like transcription factors or molecules regulating the cell cycle [11]. Accordingly, the proteasome is crucial in several inflammatory processes by regulating cytokine signalling, cell proliferation, and clearance of potentially deleterious products of inflammation and is involved in the major histocompatibility complex (MHC) class I-mediated antigen presentation (Figure 1) [12]. Therefore, proteasome modulation can alter at different levels

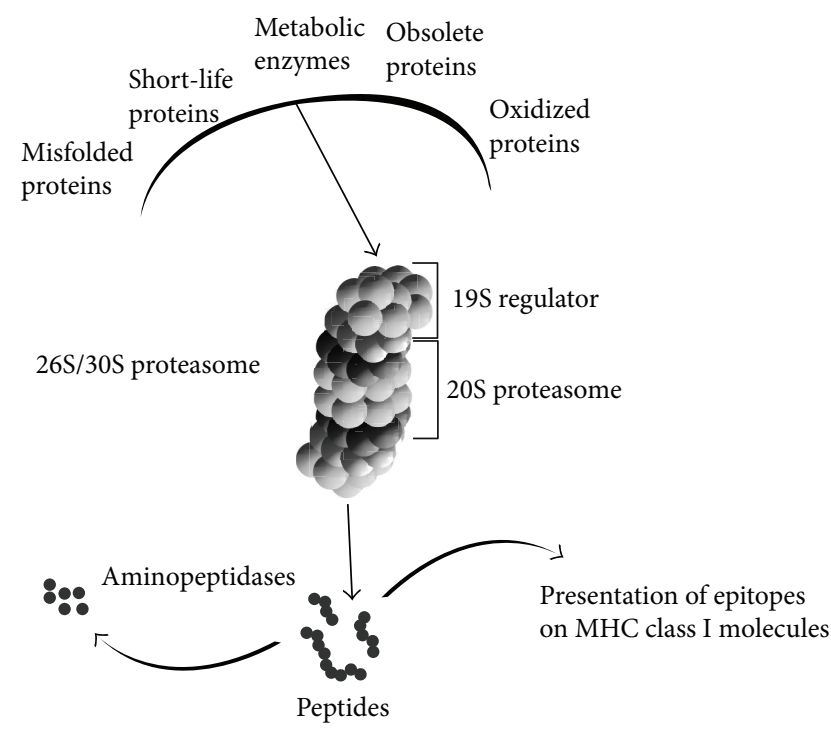

FIGURE 1: Schematic representation of the proteasome degradation pathways.

both the physiological and pathological processes of the immune system.

Different forms of proteasomes are known in eukaryotes. They vary in terms of catalytic subunits and regulatory complexes. The core $20 \mathrm{~S}$ standard proteasome (s-proteasome) is a cylinder-shaped complex, that is, composed of four stacked rings, each consisting of seven protein subunits. Among them the $\beta 1, \beta 2$, and $\beta 5$ subunits harbour the proteolytic active sites. The result of the association of the $20 \mathrm{~S}$ proteasome core to the PA700 regulators is the $26 \mathrm{~S} / 30 \mathrm{~S}$ proteasomes, which cleave polyubiquitylated proteins in an ATP-dependent manner. 20S proteasome can also bind the PA28 regulator, which alters proteasome catalytic activities $[13,14]$.

The immunoproteasome (i-proteasome) is an isoform of the $20 \mathrm{~S}$ proteasome. It carries specific catalytic subunits, that is, $\beta 1 \mathrm{i}, \beta 2 \mathrm{i}$, and $\beta 5 \mathrm{i}$ (also known as LMP2, MECL-1, and LMP7, resp.), which confer to the i-proteasome quantitative differences in cleavage preferences and substrate degradation rates compared to the s-proteasome. I-proteasome is generally synthesized upon interferon- $\gamma$ (IFN- $\gamma$ ) stimuli, but tumor necrosis factor- $\alpha$ (TNF- $\alpha$ ) or lipopolysaccharide has also been found to be involved in its inducible expression $[15,16]$. The vast majority of endogenous peptides that are presented by the MHC class I molecules at the cell surface and recognised by $\mathrm{CD}^{+} \mathrm{T}$ cells are generated by proteasomes. I-proteasome is generally linked to its high efficiency in the generation of the MHC class I-restricted epitopes. In support of this, i-proteasomes are predominantly expressed by professional antigen presenting cells (APCs), such as dendritic cells (DCs) and B cells, or in other cell types during inflammation, thereby indicating the i-proteasome as a major player of the MHC class I antigen presentation (Figure 1) $[11,17]$.

Preliminary observations on white and grey matter of MS patients suggested that the degradation rates of short 
fluorogenic peptides by $20 \mathrm{~S}$ proteasomes are decreased when compared to brain-tissue controls [18]. These results, however, cannot be interpreted as a general decrease of the proteasome-mediated proteolytic activity, as recently shown in [19-21]. Furthermore, an accumulation of i-proteasome and its regulator PA28 $\alpha \beta$ has been observed in different cell types affected by MS, such as oligodendrocytes, astrocytes, macrophages/microglia, infiltrating lymphocytes, and weakly neurons [22]. Such disease-related expression of $\mathrm{i}$-proteasome is in agreement with recent observations in the experimental model of MS, that is, the experimental autoimmune encephalomyelitis (EAE). In this model, the cerebral expression of i-proteasome and PA28 $\alpha \beta$ was increased as compared with baseline levels during the acute phase of EAE. Of note, i-proteasomes were also detected in neurons, infiltrated T lymphocytes, and microglia in EAE mice [23]. However, in this study by Zheng et al., an equal expression of $\mathrm{s}$ - and i-proteasome subunits has been described in control mouse brain, contrasting with other studies on rodents and humans which reported a faint expression of i-proteasome in young/adult brains [21, 24, 25]. Furthermore, Zheng et al. reported no differences in the i-proteasome expression by comparing young and old control mouse brains, which is in contrast to studies on other mammals such as rats $[21,26]$ and humans [27], but in agreement with a study conducted on nonhuman primates [28].

The expression of i-proteasome in MS lesions or in cells involved in MS mechanisms is important because this isoform has been recently linked to different inflammatory processes. Indeed, i-proteasomes are specifically implicated in cytokine-mediated inflammation, cell growth, and differentiation in mice [11]. I-proteasome depletion alters the $\mathrm{T}$ cell antigen receptor (TCR) repertoire formation, the number and differentiation of $\mathrm{CD}^{+} \mathrm{T}$ cells, and the production of proinflammatory cytokines [29]. In addition, i-proteasome depletion during IFN- $\gamma$-mediated oxidative stress is consistent with a deficient clearance of oxidized proteins and aggresomes [30, 31]. These events have been associated with worsening of EAE clinical score in $\beta 5 \mathrm{i}-/-$ mice [31], although discordant results have also been reported by others [32]

In the following sections we will discuss these and additional data suggesting an involvement of proteasomes in specific pathways underlying MS.

\section{I-Proteasome and $\mathrm{CD8}^{+} \mathrm{T}$ Cells in MS}

$\mathrm{CD}^{+}$and $\mathrm{CD}^{+} \mathrm{T}$ lymphocytes reactive against myelin have been found in peripheral blood, cerebrospinal fluid (CSF), and CNS plaques of MS patients, but their role in MS pathogenesis is still a matter of debate. Antimyelin $\mathrm{CD} 4^{+}$ $\mathrm{T}$ cells in MS have been widely studied because of their role in regulating cell-mediated inflammation, their ability in inducing EAE, and the identification of HLA-DRB1* ${ }^{*} 15$ allele as the most significant genetic risk factor associated with MS [33]. EAE can also be triggered by the administration of $\mathrm{CD}^{+} \mathrm{T}$ cells specific against myelin antigens in mice. In MS, $\mathrm{CD}^{+} \mathrm{T}$ cells exceed $\mathrm{CD}^{+} \mathrm{T}$ cells by $3-10$-fold in regions of demyelination, and the degree of axonal damage within MS lesions correlates with the number of $\mathrm{CD}^{+} \mathrm{T}$ cells [33]. Furthermore, several studies described an increased prevalence of $\mathrm{CD}^{+}$cytotoxic $\mathrm{T}$ cells reactive against specific myelin epitopes in peripheral blood of MS patients compared to healthy controls [34-36]. These observations, in addition to the genetic associations of HLA class I alleles with MS risk, suggest an involvement of $\mathrm{CD}^{+} \mathrm{T}$ cells in MS [33].

Because i-proteasome is a major player in the processing of MHC class I-restricted epitopes in professional APCs or in inflamed conditions, it is likely that it is also involved in the presentation of myelin antigens in the MS brain. For instance, i-proteasome expression is induced in oligodendrocytes of MS patients [22]. These cells are the main producers of myelin, and hence likely to be the target of $\mathrm{CD}^{+} \mathrm{T}$ cells in MS. Indeed, $\mathrm{CD}^{+} \mathrm{T}$ cells were observed in close proximity to oligodendrocytes and demyelinated axons in brain tissue, towards which cytolytic granules were polarized [33]. The expression of i-proteasome in oligodendrocytes might therefore alter the presentation onto the MHC class I molecules of myelin antigens and the cytotoxic activity of specific $\mathrm{CD} 8^{+} \mathrm{T}$ cells towards these cells.

Although the abovementioned scenario lacks experimental validation, there is substantial support for this theory. For instance, our group has previously observed in vitro that i-proteasome carrying a polymorphic variant at codon 60 (i.e., HH60) of $\beta 1$ i subunit produces less amount of the myelin basic protein epitope $\mathrm{MBP}_{111-119}$ [22]. This epitope is presented on the HLA-A*02 molecule, although with moderate affinity [22] and memory $\mathrm{CD}^{+}$cytotoxic $\mathrm{T}$ cells specific for this epitope are more prevalent in the blood of MS patients than controls [35-37]. We also described a lower prevalence of the $\beta 1 \mathrm{i}$ HH60 variant among MS females with HLA-A ${ }^{*} 02^{+}$genotype when compared to a matched control population. These observations led us to hypothesize that the lower risk of developing MS in HLA-A ${ }^{*} 02^{+}$subjects carrying the $\beta 1 \mathrm{i}$ HH60 variant could be-at least in part-due to a lower production of $\mathrm{MBP}_{111-119}$ by oligodendrocytes or APCs in these subjects [22].

The key role of i-proteasomes in autoreactive $\mathrm{CD}^{+} \mathrm{T}$ cell response has been recently confirmed by the observation that mice lacking i-proteasome $\beta 5 \mathrm{i}-\beta 2 \mathrm{i}$ subunits developed a multitissue autoimmune disorder mediated by $\mathrm{CD} 8^{+} \mathrm{T}$ cells via altered MHC class I-restricted self-antigen presentation [38]. The authors of the study speculated that a relatively high percentage of MHC class I molecules present "dangerous" epitopes in presence of inflammation and in the absence of i-proteasome. These self-peptides are low-affinity binders to the MHC class I complexes (as the epitope $\mathrm{MBP}_{111-119}$ [22]) and are better produced by s-proteasomes. Hence, in the absence of an appropriate i-proteasome activity these "dangerous" self-epitopes may be generated and targeted by autoreactive $\mathrm{CD}^{+}$cytotoxic $\mathrm{T}$ cells, thereby triggering an autoimmune response [38]. It is attractive to hypothesize that a similar mechanism is at work in MS and would imply that i-proteasome might hamper MS development by reducing the amount of "dangerous" self-peptides presented by APCs in periphery.

Another matter of debate relies on the mechanisms causing the disruption of the immune system tolerance and 
the activation of autoreactive $\mathrm{CD} 4^{+}$and $\mathrm{CD} 8^{+} \mathrm{T}$ lymphocytes towards CNS cells. Different studies suggest that molecular mimicry could be involved in the immune system disruption. This phenomenon describes the reaction of a single $\mathrm{T}$ cell clone to epitopes derived from both pathogen and human proteomes. It has been proposed that MS is triggered by a viral infection that, in the presence of (unknown) additional environmental and genetic factors, leads to an uncontrolled activation of autoreactive $\mathrm{T}$ cells. Such theory could explain in part the geographic distribution of the risk of developing MS [4] and is supported by several studies showing an increase of EBV-specific cellular immune responses in the blood and in the CSF of subjects with MS [5, 39-42], although the association with other viruses has also been found [4]. Conflicting results however exist about the role of molecular mimicry in driving pathological disorders associated with $\mathrm{CD}^{+} \mathrm{T}$ cells, as a comprehensive analysis on a broad range of $\mathrm{CD}^{+}$cytotoxic $\mathrm{T}$ cell clones showed a very limited number of cross-reactive $\mathrm{T}$ cells recognising both viral and self-epitopes [43].

The mechanisms of molecular mimicry related to $\mathrm{CD} 8^{+}$ $T$ cells in autoimmune disorders could be further investigated bearing in mind another proteasome-mediated process, named proteasome-catalyzed peptide splicing (PCPS). PCPS occurs through the binding of separate peptide fragments originating from a single protein, that is, cis-PCPS, or from two distinct protein segments, that is, trans-PCPS (Figure 2) [44-46]. The role of PCPS in MS has not been investigated yet, although it might be relevant for several reasons. Firstly, PCPS is more prone to generate MHC class I-restricted potential epitopes than the simple proteasomal peptide hydrolysis because of specific biochemical features of PCPS [47]. In addition, PCPS highly increases the diversity of MHC class I-restricted epitopes from self- and viral-antigens as the number of potential peptides presented on MHC molecules is several times higher than the number of peptides encoded in the proteome [48]. Consequently, through the PCPS there could be a significant increase of MHC class I-restricted epitopes with high sequence homology to viral and human proteomes. This phenomenon implies that the activation of $\mathrm{CD} 8^{+} \mathrm{T}$ cells specific for "spliced" viral epitopes with high or even complete homology with myelin antigens could represent a threat against myelin-producing cells and eventually take part in the development of MS.

\section{Th17 Cells, Gut Microbiota, and Proteasome in MS}

$\mathrm{CD}^{+} \mathrm{T}$ cells become activated by recognising antigens presented onto the MHC class II molecules, which are only expressed on professional APCs (such as DCs, macrophages, and $\mathrm{B}$ cells). Upon antigen stimulus, $\mathrm{CD} 4^{+} \mathrm{T}$ lymphocytes differentiate into two main subpopulations, $\mathrm{T}$ helper type 1 (Th1) cells and Thelper type 2 (Th2) cells. Activated $\mathrm{CD} 4^{+} \mathrm{T}$ cells can also differentiate into regulatory $\mathrm{T}$ (Treg) cells, which are characterised by the expression of the forkhead box P3 (FoxP3) transcription factor [49].

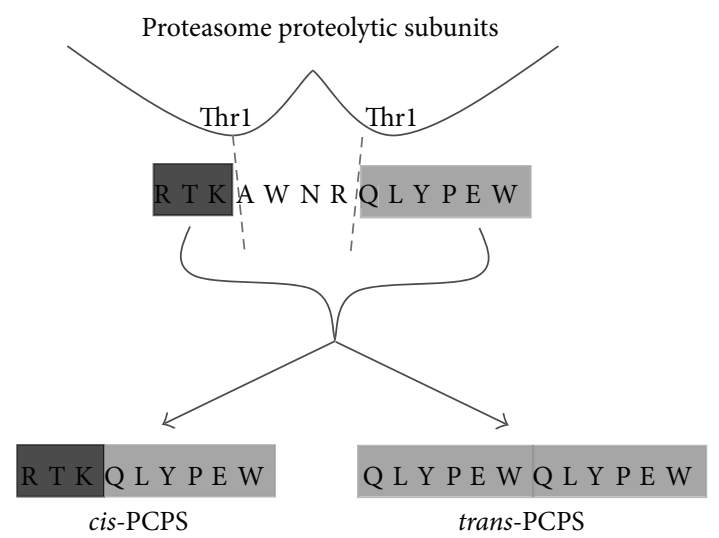

FIGURE 2: Proteasome-catalyzed peptide splicing (PCPS). PCPS can occur by ligation of two fragments of the same substrate molecule (cis-PCPS) or derived from two distinct protein molecules (trans-PCPS). Shown here are the representative cleavages (depicted by dotted lines) of the peptide gp100 $0_{40-52}$ (sequence: RTKAWNRQLYPEW) by two distinct proteasome catalytic subunits, which generate the fragments RTK, AWNR, and QLYPEW. According to the PCPS model $[44,47]$, the protein is first cleaved by the active site residue Thrl of the proteasome proteolytic subunits, thereby producing a protein fragment. The latter peptide stays attached to the catalytic centre where, subsequently, it is ligated to a second peptide generating the proteasome-generated spliced peptide.

More recently, a new T cell subpopulation, the Th17 cells, which secretes IL-17, IL-21, and IL-22, has been described and associated with the control of extracellular pathogens [50]. Th17 cells and their cytokines are associated with several autoimmune and inflammatory diseases, such as rheumatoid arthritis, systemic lupus erythematosus, MS, psoriasis, inflammatory bowel disease, allergy, and asthma [51]. In MS patients, IL-17 expression is increased in blood mononuclear cells and in CSF as well as at the site of lesions [52]. IL-17 and IL-22 promote blood-brain barrier permeability and CNS inflammation by inducing chemokine production in endothelial cells and by downregulating tight junction proteins. IL-17 also stimulates astrocytes to produce CXC chemokines that can attract neutrophils to the BBB and activate them to release vasoactive substances [53]. It has been shown that myelin-specific Thl7 cells directly interact with neuronal cells in demyelinating lesions [54]. Either deficiency or neutralization of IL-17 delay the onset and reduce the severity of EAE [55]. Furthermore, IL-23 expands Th17 cells and is critical for the induction of EAE. In contrast, a recent paper reported that overexpression of IL-2 in vivo reverses EAE pathology by decreasing the Th1 and Thl7 infiltration. Notably, under inflammatory conditions (such as in EAE), Th17 cells display plasticity because these cells can change phenotype in inflamed tissues and secrete proinflammatory cytokines such as IFN- $\gamma$ instead of IL-17 [56].

A modifier of Th17 cell response in MS may be gut bacteria, which play an important role in shaping intestinal $\mathrm{CD} 4^{+}$ $\mathrm{T}$ cell responses [57] and in affecting brain inflammation, as suggested by evidence on gut-brain communication $[58,59]$. 
The mammalian gastrointestinal track harbors a highly heterogeneous population of microbial organisms, which vary across geographical areas and are essential for the complete development of the immune system. The gut microbes or "microbiota" also drive a swarm of T cell responses in the gut. For instance, segmented filamentous bacteria trigger intestinal Th17 cell responses; indeed when these bacteria are used to monocolonize germ-free mice they restore Th17 cell responses in the lamina propria of the small intestine [60]. Gut bacteria are also critically involved in the differentiation of some Treg cell subsets [61] as these specific microbial organisms have developed distinct ways to promote effector $\mathrm{T}$ cells or Treg cell differentiation in the gut [62]. The Treg/Th17 ratio and also the Treg cell frequency have been negatively correlated with MS severity [63], thereby suggesting that the measure of their balance could be an informative biomarker for evaluating or comparing the effectiveness of MS therapies.

In the context of MS models, it has been reported that the treatment of EAE mice with probiotics reduces neuroinflammation [64] and that different gut microbiota could induce $[34,65]$ or tackle CNS inflammation [66]. In addition, antibiotic-mediated depletion of the gut microbiota reduces the EAE severity and the levels of proinflammatory cytokines and chemokines, whereas it increases the levels of the anti-inflammatory cytokines IL-10 and IL-13. Moreover, IL-10-producing FoxP3+ Treg cells accumulate in the cervical lymph nodes of antibiotic-treated mice and protect naïve recipients against the transfer of EAE [65].

The tight connection between commensal gut microbiota, EAE, and Th17 lymphocytes has been recently investigated in two different models of EAE. Lee and colleagues [67] studied the induction of EAE by immunizing germ-free bacteria, specific-pathogen-free and control mice with $\mathrm{MOG}_{35-55}$ peptide + Mycobacterium tuberculosis. They observed that germ-free mice are highly resistant to EAE development and have a lower prevalence of Th17 and Th1 cells leading to the conclusion that there is a hampering of the systemic and neuronal proinflammatory Th17 and Th1 response during EAE in absence of commensal microbiota in mice. This phenomenon seems to be reversible because intestinal colonization with segmented filamentous bacteria in germ-free mice promotes EAE development. They concluded that the microbiota dynamically and reversibly impacts the programming of pathogenic immune response during autoimmunity and that microbial colonization may provide proinflammatory signals that affect the reciprocal development of Th and Treg cells both in gut and in CNS [67].

In a second article, Berer and colleagues [68] reported that germ-free mice develop less frequently EAE, a phenomenon accompanied by a reduced number of Th17 cells in the lamina propria and reduced secretion of IL-17 and IFN- $\gamma$ by splenic $\mathrm{T}$ cells in response to cognate antigen stimulation. In this latter study, a spontaneous remitting-relapsing EAE mouse model has been used. These mice express, in a large proportion of their $\mathrm{CD}^{+} \mathrm{T}$ cells, a transgenic TCR that recognizes $\mathrm{MOG}_{92-106}$ peptide in the context of $\mathrm{MHC}$ class II molecules [68]. The fact that two independent studies described, in different models of EAE, an impairment of Th17-mediated induction of EAE in germ-free mice supports the hypothesis that gut microbiota may influence MS via Th17 cell activity.

Another modifier of the Th17 cell response in MS may be the i-proteasome. Indeed, it has been shown that the in vitro administration of $\mathrm{i}$-proteasome $\beta 5 \mathrm{i}$ subunit inhibitor prevents the early activation of $\mathrm{CD} 4^{+} \mathrm{T}$ cells, their differentiation into Th17 cells, and the secretion of TNF- $\alpha$, IL-23, and IL6 [69]. In vivo, $\beta 5 \mathrm{i}$ inhibition or deficiency results in reduced Th1 and Th17 cell expansion and Treg cell development through STAT3/STAT1/SMAD phosphorylation [70]. The treatment with $\beta 5 \mathrm{i}$ subunit inhibitor also attenuates the progression of the experimental arthritis in mice [69]. Because this phenomenon acts on the Th17 differentiation pathway and it is not observed by inhibiting s-proteasome activity, we may speculate that a selective block of $\mathrm{i}$-proteasome $\beta 5 \mathrm{i}$ subunit in mice might also tackle the development of EAE. Preliminary evidence in dextran sodium sulfate-induced colitis indirectly support such speculation, since this animal model mimics inflammatory bowel diseases, such as Crohn's disease and ulcerative colitis, which are characterized by a marked mucosal infiltration of T cells that secrete Th1 and Th17 cytokines and alterations of faecal and mucosal bacterial communities [71]. Interestingly, in $\beta 5 \mathrm{i}$ subunit $-/-$ mice and in wild type mice treated with a proteasome inhibitor, there is a reduction in the secretion of proinflammatory cytokines and chemokines, the infiltration into the colon by neutrophils, and the expansion of Th1 and Th17 cells, thereby preventing excessive tissue damage [72]. These observations are in agreement with the results of Basler et al. [73], which showed a role of $\beta 5 \mathrm{i}$ subunit inhibition in reducing the production of proinflammatory cytokines, inflammation, tissue destruction, and consequently pathological symptoms of experimental colitis.

These data suggest that in EAE the activity of Th17 cells could be regulated by gut microbiota and i-proteasomes. Therefore, both of them may be potential targets for the treatment of MS, although there are no studies that investigated the direct interaction between gut microbiota and i-proteasome in EAE.

\section{Humoral Immunity, Proteasomes, and MS}

The understanding of MS pathogenesis has been mostly driven by studies on $T$ cells and their inflammatory cytokines produced in damaged tissues [74]. The interest regarding the antibody-dependent as well as antibody-independent B cell involvement has received a strong boost from the success of clinical trials targeting B cells in MS and other autoimmune diseases $[75,76]$.

Beyond their ability to produce antibodies, B cells function as APC, thereby contributing to $\mathrm{T}$ cells activation in the CNS [77]. They also influence the immune response through the production of effector cytokines, such as those involved in immune regulation (e.g., anti-inflammatory IL10 ), polarization (IL-4), and cytokines involved in lymphoid tissue organization (e.g., TNF- $\alpha$ and leukotrienes) [78]. Remarkably, decreased levels of IL-10 and increased concentrations of TNF- $\alpha$ and leukotrienes have been described in 
patients affected by MS [79], thus contributing to abnormal T-cell activation. This fact provides a conceivable mechanism of action to explain why B cell depletion may be relevant, both in the periphery and in the CNS, in diminishing new MS activity [79]. Indeed, Rituximab, a monoclonal antibody against CD20 molecules, exerts its therapeutic effect through a rapid and profound depletion of peripheral $B$ cell, along with a significant reduction in the volume of T2 lesions and clinical relapse in the RRMS patients, and a reduced disease progression in PPMS [80, 81]. Additionally, in a small cohort of PPMS, it has been shown that Rituximab temporarily suppresses the activation of B cells in CSF [82]. However, the presence of regulatory $B$ cell subsets (B regs), which could either induce or inhibit immune response, accounts for the variable effects that targeting B cells may have in vivo [77-80]. At present, new monoclonal antibodies (i.e., Ocrelizumab, Ofatumumab) targeting CD20 or specific surface markers of $B$ cell subset (i.e, Atacicept) are under investigation in phase II/II trials $[83,84]$.

Although at present there is no data available on proteasome isoforms, B cell regulation, and MS, the recent observation of Hensley et al. [85] is relevant to connect all these three topics. Indeed, the authors reported that $\mathrm{i}$ proteasome $\beta$ li subunit $-/-$ mice have a defect in B cells maturation and Ig isotope switch upon viral infection as well as in $\mathrm{CD} 4^{+} \mathrm{T}$ cell survival and DC activation. They identified in the NF- $\kappa \mathrm{B}$ activation one of the pathways affected by the presence of intermediate type proteasomes instead of the i-proteasome, which is normally present in these cells. A role of i-proteasome in modulating NF- $\kappa \mathrm{B}$ signalling has also been observed by Maldonado and coworkers [86] in retinal pigment epithelial cells of $\beta 1$ subunit -/- mice. In knockout mice a higher content and a diminished activation of the NF- $\kappa \mathrm{B}$ alternative pathway, as well as a delayed termination of the classical pathway, after in vitro stimulation by TNF- $\alpha$, has been observed compared to wild type littermates [86].

Concerning the role and significance of antibodies in MS patients, the presence of CSF oligoclonal bands and increased immunoglobulin IgG synthesis is a frequent feature of MS [87] as well as other localized autoimmune diseases of the CNS [88]. These pathogenic autoantibodies (autoAbs) can induce tissue damage and thus be involved in plaque initiation and demyelination by recruiting macrophages and by complement deposition in white matter lesion of MS patients [89]. However, the antigenic targets of these antibodies and their potential use as biomarkers of MS are still a matter of debate. Indeed, autoAbs against antigens not specific for the CNS have also been associated with MS, although it is unclear if they are pathogenic effectors instead of being secondary products of the release of antigens upon CNS tissue damage. Proteasome Abs, for example, are elevated in sera of RR-, PP-, and SP-MS patients compared to other autoimmune diseases or healthy controls [90-92]. It has been shown in vitro that autoAbs against $20 \mathrm{~S}$ proteasome block the proteasome activation by PA28 regulator, thereby suggesting that these autoAbs might have a regulatory function towards extracellular proteasomes such as circulating proteasomes [93]. Notably, although proteasomes are mainly studied as intracellular proteases, extracellular circulating proteasomes are normally present in peripheral blood, and their levels are significantly increased in a variety of pathological conditions, including autoimmune diseases and tumours [94]. In particular, as biomarkers of ongoing pathological mechanisms, circulating proteasomes have demonstrated to have prognostic power as regards therapy outcome and survival in multiple myeloma patients [95]. Although cells originating extracellular proteasomes detected in peripheral blood and in the CSF have not been identified, an active release of circulating proteasomes has been recently proposed [96] as they have been copurified with exosomes [97]. In line with this hypothesis, the immunological activity rather than the cellular damage has been suggested as the causative mechanism for increased circulating proteasome levels in sepsis and sever injury [98]. Recently, a preliminary study carried out on a limited number of patients affected by RRMS has shown that circulating proteasome amount increases in MS and even further in MS patients treated with IFN- $\beta$. The authors have also described a specific proteasome activity pattern in plasma of MS patients although they have not reported appropriate control experiments with proteasome inhibitors [99]. This preliminary observation, however, might be relevant for future studies. Indeed, a fascinating speculation is that circulating proteasomes in peripheral blood are not only simple biomarkers of inflammatory status, but also active proteases that might control cytokine levels, cell-mediated cytotoxicity, and plasma membrane permeability [94] and synergize with other component to ameliorate tissue damage [97].

\section{Maintenance of Cellular Homeostasis during Inflammation-Mediated Oxidative Stress in MS}

The pathological mechanisms of neurodegeneration, although largely unknown, are often mediated by oxidative stress and excitotoxicity (degenerative cascade), two processes that are closely interactive $[100,101]$. The increased production of reactive oxygen and nitrogen species induces oxidative damage to different cellular components including lipid, DNA, and proteins [102]. Accordingly, in MS patients, oxidized DNA is present in a small number of reactive astrocytes as well as in oligodendrocyte nuclei, with evidence of apoptosis [103]. Similarly, lipid peroxidation-derived structures (malondialdehyde and oxidized phospholipid epitopes) can be detected in the cytoplasm of oligodendrocytes and some astrocytes as well as in degenerating neurons within grey matter lesions [103]. Oxidized proteins are more prevalent in cerebellar astrocytes as well as in spinal cord neurons of EAE mice [104, 105]. In such scenario, an effective removal of oxidized proteins seems to be a key element to maintain cellular homeostasis during neuroinflammation.

Studies performed on neuronal cell lines have suggested that proteasome plays a central role in mitochondria homeostasis. Proteasome inhibition decreases the activity of complexes I and II and increases the production of reactive oxygen species and the accumulation of lipofuscin, 
a highly oxidized cross-linked aggregate of oxidized protein and lipid [106, 107]. In addition, proteasome is essential in maintaining cell homeostasis by degrading obsolete, damaged, and oxidized proteins [108-112]. Notably, the 20S proteasomes are more resistant to oxidative stress than $26 \mathrm{~S}$ proteasomes and seem to be able to degrade oxidized proteins in an ATP-independent manner [113, 114]. Furthermore, $\mathrm{i}$-proteasome expression is induced during oxidative stress in several inflammatory-based diseases in the CNS and in peripheral organs $[30,115,116]$ and it provides enhanced cellular resistance to oxidative stress, at least in part by an increased degradation rate of oxidized proteins compared to s-proteasome [117]. Indeed, the blocked expression of $\beta 1 \mathrm{i}$ subunit by siRNA significantly reduces the adaptive response to mild oxidative stress in mouse embryonic fibroblasts [116], $\beta 5 \mathrm{i}$-depleted retinal pigment epithelial cell viability is more compromised than wild type cells [30], and $\beta 1$ i subunit -/mice exhibit higher levels of protein carbonyls in brain and liver upon aging than those of their wild type littermates [118]. Accordingly, Seifert and coworkers [31] have shown an accumulation of oxidized and polyubiquitylated proteins and aggresome-like induced structures upon INF- $\gamma$ stimuli in the liver and brain of $i$-proteasome $\beta 5 i$ subunit $-/-$ mice. Moreover, $\beta 5$ i subunit deficient cells and tissues are not only more sensitive to apoptosis but also have a delayed activation of NF- $\kappa$ B after TNF- $\alpha$ stimulation [31]. This dependence of protein oxidation clearance on i-proteasome activity might be pivotal for MS because i-proteasome $\beta 5$ i subunit -/- mice showed an earlier onset and worse clinical score than wild type mice in an EAE model [31] although this fact, recently, has been disputed by Nathan and colleagues [32].

Overall, these results suggest that i-proteasomes may influence onset and progression of MS by affecting the response of different cell types to the inflammatory aggression in the CNS.

\section{Is Proteasome Inhibition a Potential Therapy of MS?}

The administration of immunomodulatory drugs (glatiramer acetate and IFN- $\beta$ ) represents the first line therapy for RRMS, but these drugs are seldom useful towards the progressive form of MS [119]. The partial or total inefficacy of the common MS treatments in SPMS and PPMS patients demands the identification of novel therapies. The progressive forms of MS seem to be characterized by peculiar immunological mechanisms that differ from RRMS. In PPMS and SPMS the whole brain is affected and inflammation as well as axonal injury is diffuse, whereas in RRMS inflammation and tissue damage are more focalized in plaques [120]. In the progressive forms of MS, the $\mathrm{CD}^{+}$and $\mathrm{CD}^{+}{ }^{+}$T cells and the $\mathrm{B}$ cells seem to be part of the pathological mechanisms, although with characteristics that differ from those observed in RRMS and without a clear correlation between immune cell activation and clinical measures of disease duration and severity, especially in PPMS [121]. Considering the complex pathogenic mechanisms at the basis of MS development, further studies would be needed to better characterize the role of different immune system players, including proteasomes, autoAbs as well as specific Th17 and $\mathrm{CD}^{+} \mathrm{T}$ cells, in the different forms of MS. These studies are likely to support the discovery of new diagnostic and prognostic biomarkers for different MS forms and to generate novel therapeutic drugs such as the specific proteasome inhibitors. Indeed, proteasome inhibitors have been utilised as therapeutic approach towards other diseases, such as multiple myeloma, and selective inhibitors for s- or i-proteasome have been recently developed [122].

Two factors could influence the success of novel therapies based on proteasome inhibitors: their toxicity profiles and their delivery pathways to the CNS and/or the periphery. Regarding the former, the experience of the first proteasome inhibitor, named Bortezomib, approved for clinical treatment of hematologic malignancies, showed that the toxicity could be a limiting factor [122]. However, this disadvantage can be controlled with new inhibitors specific for i-proteasome subunits that can therefore block proteasome activity only in specific cells or pathological conditions [122]. In such contest, the induction of $\mathrm{i}$-proteasome expression in specific cell types upon MS onset-reviewed in Section 1-is a pivotal element ought to be borne in mind.

An additional critical issue is drug delivery. Indeed, the inhibition of i-proteasome is detrimental in tackling the oxidative stress during inflammation, leading to the accumulation of oxidised proteins [11]; this has been linked to the disputed observation that the depletion of $\beta 5 \mathrm{i}$ subunit anticipated EAE onset [31, 32] (Table 1). However, further investigations have to be performed since the blockage of i-proteasome activity resulted in a decreased expression of inflammatory biomarkers in ex vivo analyses of microglia of a mouse model of Alzheimer's disease [19]. Conversely, an inhibition of i-proteasomes limited to the periphery and towards immune system components such as B and Th17 lymphocytes might be beneficial in treating MS. Noteworthy, the promising results of the clinical trials with the monoclonal antibody Rituximab for the treatment of MS (see Section 4) are consistent with the hypothesis that also a depletion of $\mathrm{B}$ cells might ameliorate MS disease. In mice, such depletion could be achieved by a defect in $\beta 1$ i subunit expression [85] (Table 1).

Furthermore, Th17 cells could be targeted for ameliorating MS course. As i-proteasome inhibition decreases the activation of Th17 cells in mice $[69,70]$, it can be envisaged that i-proteasome inhibitors could be used to limit Th17 cell activation and EAE progression in mice (Table 1). The first test of this hypothesis could be obtained by treating EAE mice with inhibitors of the $i$-proteasome $\beta 5 i$ subunit, as it has been already done for other experimental disease models [69, 73]. Notably, a blockage of the i-proteasome activity along the Th17 cell pathway could be coupled to the therapeutic administration of probiotics (live beneficial bacteria) or prebiotics (compounds that stimulate the growth of beneficial bacteria) in EAE mice, given their common action on Th17 lymphocytes $[67,68]$. Nonetheless, whether the modulation of gut microbiota could have similar beneficial effects also on MS is largely unknown. In EAE, the depletion or the strong modification of gut microbiota showed beneficial effects on the development of the disease [67, 68]. However, unlike 
TABLE 1: Proteasome isoforms as potential targets of immunological pathways. The table summarizes the major results that may help future studies to understand how the inhibition of distinct proteasome isoforms may affect the development and progression of MS.

\begin{tabular}{|c|c|c|c|c|c|}
\hline Final targets ${ }^{\mathrm{a}}$ & Anatomic area & Proteasome subunits inhibited $^{\mathrm{b}}$ & MS forms & Potential effects ${ }^{c}$ & References \\
\hline $\mathrm{CD}^{+} \mathrm{T}$ cells & Thymus, lymph nodes, CNS & $\beta 1 \mathrm{i}, \beta 2 \mathrm{i}, \beta 5 \mathrm{i}$ & NA & $+/-$ & $\begin{array}{c}{[22,29,38,123} \\
124]\end{array}$ \\
\hline $\mathrm{CD}^{+}$Th17 cells & Thymus, lymph nodes, CNS, gut & $\beta 1 \mathrm{i}, \beta 2 \mathrm{i}, \beta 5 \mathrm{i}$ & NA & + & $\begin{array}{c}{[51,67,68,70} \\
72,73]\end{array}$ \\
\hline B cells & Thymus, lymph nodes, CNS & $\beta 1 \mathrm{i}$ & RR, PP, SP & + & {$[80,81,85]$} \\
\hline Proteasome Abs & Serum & NA & RR, PP, SP & NA & {$[90]$} \\
\hline $\begin{array}{l}\text { Circulating } \\
\text { proteasome }\end{array}$ & Serum & NA & NA & NA & {$[94,99]$} \\
\hline CNS parenchyma & CNS & $\beta 5 \mathrm{i}$ & NA & - & [31] \\
\hline
\end{tabular}

mouse models, the human being has a broad variety of diet, environment, genetics, and early microbial exposure features that lead to highly diversified microbiota, which is furthermore extremely adaptable and variable over time $[125,126]$. Therefore, the identification of a beneficial or detrimental microbiota towards MS might be strenuous.

While the potential inhibition of i-proteasome activity in $B$ and Th17 cells points towards a beneficial effect against MS, the knowledge of the role of circulating proteasome and of proteasome Abs remains poor. Because of high levels of circulating proteasomes and proteasome Abs in the serum of MS patients [90,99] a tempting speculation is that the production of proteasome Abs might aim to affect the circulating proteasome activity, although the role of circulating proteasomes in MS and more in general in the peripheral blood is largely unknown (Table 1). Further studies are mandatory to investigate such an issue because a therapy with proteasome inhibitors delivered through peripheral blood would immediately affect circulating proteasomes.

The potential effects of an i-proteasome inhibition within the $\mathrm{CD}^{+} \mathrm{T}$ cell-mediated immune response are still unclear. This inhibition could affect therapy outcome depending on whether the drug is delivered in the periphery only or also in the CNS. Indeed, i-proteasome could influence the presentation of endogenously produced myelin antigens in oligodendrocytes (i.e., in CNS) and in bone marrow-derived APCs (i.e., in periphery) $[123,127]$, although the outcome of the activation of antimyelin $\mathrm{CD}^{+} \mathrm{T}$ cells is still a matter of debate. For instance, in transgenic mice the induction of EAE by HLA-A*03-restricted myelin epitope was hampered by the overexpression of HLA-A*02 molecules, confirming the opposite (and interacting) action of MHC class I-restricted myelin epitopes on EAE onset [124]. Furthermore, it has been hypothesized that the expression of $\mathrm{i}$-proteasome limits the generation of self-epitopes associated with autoimmune responses [38] and we have proposed that a link exists between a genetic protection toward MS and an i-proteasome polymorphism that impairs the generation of a specific MBP epitope [22]. We therefore conclude that i-proteasomes could play a role in the $\mathrm{CD}^{+} \mathrm{T}$ cell-mediated immune response in MS, and further studies shall better define the role of $\mathrm{CD}^{+}$
T cells in this pathology and identify which epitopes trigger a deleterious autoimmune $\mathrm{CD}{ }^{+} \mathrm{T}$ cell reaction and how they are generated by different proteasome isoforms.

\section{Abbreviations}

$\begin{array}{ll}\text { APC: } & \text { Antigen presenting cells } \\ \text { AutoAbs: } & \text { Autoantibodies } \\ \text { BBB: } & \text { Blood-brain barrier } \\ \text { CNS: } & \text { Central nervous system } \\ \text { CSF: } & \text { Cerebrospinal fluid } \\ \text { DCs: } & \text { Dendritic cells } \\ \text { EAE: } & \text { Experimental autoimmune encephalitis } \\ \text { FoxP3: } & \text { Forkhead box P3 } \\ \text { IFN: } & \text { Interferon } \\ \text { Ig: } & \text { Immunoglobulin } \\ \text { IL: } & \text { Interleukin } \\ \text { I-proteasome: } & \text { Immunoproteasome } \\ \text { MHC: } & \text { Major histocompatibility complex } \\ \text { MBP: } & \text { Myelin basic protein } \\ \text { MOG: } & \text { Myelin oligodendrocyte glycoprotein } \\ \text { MS: } & \text { Multiple sclerosis } \\ \text { PPMS: } & \text { Primary progressive MS } \\ \text { PCPS: } & \text { Proteasome-catalyzed peptide splicing } \\ \text { RRMS: } & \text { Relapsing-remitting MS } \\ \text { SPMS: } & \text { Secondary progressive phase MS } \\ \text { S-proteasome: } & \text { Standard proteasome } \\ \text { TcR: } & \text { T cell antigen receptor } \\ \text { Th: } & \text { T helper cells } \\ \text { TNF- } \alpha: & \text { Tumor necrosis factor- } \alpha \\ \text { Treg: } & \text { Regulatory T cells } \\ \text { UPS: } & \text { Ubiquitin-proteasome system. } \\ \end{array}$

\section{Conflict of Interests}

The authors declare that there is no conflict of interests regarding the publication of this paper. 


\section{Acknowledgments}

This work was financed in part by the grant Giovani Ricercatori 2007 from the Italian Ministry of Health, by the grant AICE-FIRE 2012 from AICE FIRE Onlus Emilia Romagna, and by Onyx Pharmaceuticals to MM.

\section{References}

[1] E. M. Frohman, M. K. Racke, and C. S. Raine, "Multiple sclerosis. The plaque and its pathogenesis," The New England Journal of Medicine, vol. 354, no. 9, pp. 942-955, 2006.

[2] P. K. Stys, G. W. Zamponi, J. van Minnen, and J. J. Geurts, "Will the real multiple sclerosis please stand up?" Nature Reviews Neuroscience, vol. 13, no. 7, pp. 507-514, 2012.

[3] A. Compston and A. Coles, "Multiple sclerosis," The Lancet, vol. 372, no. 9648, pp. 1502-1517, 2008.

[4] G. Giovannoni and G. Ebers, "Multiple sclerosis: the environment and causation," Current Opinion in Neurology, vol. 20, no. 3, pp. 261-268, 2007.

[5] S. Jilek, M. Schluep, A. Harari et al., "HLA-B7-restricted EBVspecific CD8+ T cells are dysregulated in multiple sclerosis," Journal of Immunology, vol. 188, no. 9, pp. 4671-4680, 2012.

[6] L. Fugger, M. A. Friese, and J. I. Bell, "From genes to function: the next challenge to understanding multiple sclerosis," Nature Reviews Immunology, vol. 9, no. 6, pp. 408-417, 2009.

[7] B. D. Trapp and K.-A. Nave, "Multiple sclerosis: an immune or neurodegenerative disorder?" Annual Review of Neuroscience, vol. 31, pp. 247-269, 2008.

[8] A. L. Goldberg, "Functions of the proteasome: from protein degradation and immune surveillance to cancer therapy," Biochemical Society Transactions, vol. 35, no. 1, pp. 12-17, 2007.

[9] B. Dahlmann, "Role of proteasomes in disease," BMC Biochemistry, vol. 8, no. 1, article S3, 2007.

[10] F. Schmidt, B. Dahlmann, H. K. Hustoft et al., "Quantitative proteome analysis of the $20 \mathrm{~S}$ proteasome of apoptotic Jurkat $\mathrm{T}$ cells," Amino Acids, vol. 41, no. 2, pp. 351-361, 2011.

[11] F. Ebstein, P.-M. Kloetzel, E. Krüger, and U. Seifert, "Emerging roles of immunoproteasomes beyond MHC class I antigen processing," Cellular and Molecular Life Sciences, vol. 69, no. 15, pp. 2543-2558, 2012.

[12] A. M. Weissman, N. Shabek, and A. Ciechanover, "The predator becomes the prey: regulating the ubiquitin system by ubiquitylation and degradation," Nature Reviews Molecular Cell Biology, vol. 12, no. 9, pp. 605-620, 2011.

[13] M. Bochtler, L. Ditzel, M. Groll, C. Hartmann, and R. Huber, "The proteasome," Annual Review of Biophysics and Biomolecular Structure, vol. 28, pp. 295-317, 1999.

[14] D. Voges, P. Zwickl, and W. Baumeister, "The 26S proteasome: a molecular machine designed for controlled proteolysis," Annual Review of Biochemistry, vol. 68, pp. 1015-1068, 1999.

[15] C. Pintado, M. P. Gavilán, E. Gavilán et al., "Lipopolysaccharideinduced neuroinflammation leads to the accumulation of ubiquitinated proteins and increases susceptibility to neurodegeneration induced by proteasome inhibition in rat hippocampus," Journal of Neuroinflammation, vol. 9, no. 1, article 87, 2012.

[16] D. A. Ferrington and D. S. Gregerson, "Immunoproteasomes: structure, function, and antigen presentation," Progress in Molecular Biology and Translational Science, vol. 109, pp. 75-112, 2012.
[17] N. Qureshi, D. C. Morrison, and J. Reis, "Proteasome protease mediated regulation of cytokine induction and inflammation," Biochimica et Biophysica Acta, vol. 1823, no. 11, pp. 2087-2093, 2012.

[18] J. Zheng and O. A. Bizzozero, "Decreased activity of the 20S proteasome in the brain white matter and gray matter of patients with multiple schlerosis," Journal of Neurochemistry, vol. 117, no. 1, pp. 143-153, 2011.

[19] M. Orre, W. Kamphuis, S. Dooves et al., "Reactive glia show increased immunoproteasome activity in Alzheimer's disease," Brain, vol. 136, no. 5, pp. 1415-1431, 2013.

[20] S. Gohlke, M. Mishto, K. Textoris-Taube et al., "Molecular alterations in proteasomes of rat liver during aging result in altered proteolytic activities," Age, 2013.

[21] C. Giannini, A. Kloss, S. Gohlke et al., "Poly-ub-substratedegradative activity of $26 \mathrm{~S}$ proteasome is not impaired in the aging rat brain," PLoS ONE, vol. 8, no. 5, Article ID e64042, 2013.

[22] M. Mishto, E. Bellavista, C. Ligorio et al., "Immunoproteasome LMP $260 \mathrm{HH}$ variant alters MBP epitope generation and reduces the risk to develop multiple sclerosis in Italian female population," PLoS ONE, vol. 5, no. 2, Article ID e9287, 2010.

[23] J. Zheng, A. Dasgupta, and O. A. Bizzozero, "Changes in 20S subunit composition are largely responsible for altered proteasomal activities in experimental autoimmune encephalomyelitis," Journal of Neurochemistry, vol. 121, no. 3, pp. 486-494, 2012.

[24] M. Mishto, C. Ligorio, E. Bellavista et al., "Immunoproteasome expression is induced in mesial temporal lobe epilepsy," Biochemical and Biophysical Research Communications, vol. 408, no. 1, pp. 65-70, 2011.

[25] M. Kremer, A. Henn, C. Kolb et al., "Reduced immunoproteasome formation and accumulation of immunoproteasomal precursors in the brains of lymphocytic choriomeningitis virusinfected mice," Journal of Immunology, vol. 185, no. 9, pp. 5549$5560,2010$.

[26] M. P. Gavilán, A. Castaño, M. Torres et al., "Age-related increase in the immunoproteasome content in rat hippocampus: molecular and functional aspects," Journal of Neurochemistry, vol. 108, no. 1, pp. 260-272, 2009.

[27] M. Mishto, E. Bellavista, A. Santoro et al., "Immunoproteasome and LMP2 polymorphism in aged and Alzheimer's disease brains," Neurobiology of Aging, vol. 27, no. 1, pp. 54-66, 2006.

[28] E. Bellavista, M. Mishto, A. Santoro, C. Bertoni-Freddari, R. B. Sessions, and C. Franceschi, "Immunoproteasome in Macaca fascicularis: no age-dependent modification of abundance and activity in the brain and insight into an in silico structural model," Rejuvenation Research, vol. 11, no. 1, pp. 73-82, 2008.

[29] M. Groettrup, C. J. Kirk, and M. Basler, "Proteasomes in immune cells: more than peptide producers?" Nature Reviews Immunology, vol. 10, no. 1, pp. 73-78, 2010.

[30] S. A. Hussong, R. J. Kapphahn, S. L. Phillips, M. Maldonado, and D. A. Ferrington, "Immunoproteasome deficiency alters retinal proteasome's response to stress," Journal of Neurochemistry, vol. 113, no. 6, pp. 1481-1490, 2010.

[31] U. Seifert, L. P. Bialy, F. Ebstein et al., "Immunoproteasomes preserve protein homeostasis upon interferon-induced oxidative stress," Cell, vol. 142, no. 4, pp. 613-624, 2010.

[32] J. A. Nathan, V. Spinnenhirn, G. Schmidtke, M. Basler, M. Groettrup, and A. L. Goldberg, "Immuno- and constitutive proteasomes do not differ in their abilities to degrade ubiquitinated proteins," Cell, vol. 152, no. 5, pp. 1184-1194. 
[33] M. A. Friese and L. Fugger, "Autoreactive CD8+ T cells in multiple sclerosis: a new target for therapy?" Brain, vol. 128, no. 8, pp. 1747-1763, 2005.

[34] H. Yokote, S. Miyake, J. L. Croxford, S. Oki, H. Mizusawa, and T. Yamamura, "NKT cell-dependent amelioration of a mouse model of multiple sclerosis by altering gut flora," The American Journal of Pathology, vol. 173, no. 6, pp. 1714-1723, 2008.

[35] T. Tsuchida, K. C. Parker, R. V. Turner, H. F. McFarland, J. E. Coligan, and W. E. Biddison, "Autoreactive CD8+ Tcell responses to human myelin protein-derived peptides," Proceedings of the National Academy of Sciences of the United States of America, vol. 91, no. 23, pp. 10859-10863, 1994.

[36] A. Jurewicz, W. E. Biddison, and J. P. Antel, "MHC class Irestricted lysis of human oligodendrocytes by myelin basic protein peptide-specific CD8 T lymphocytes," Journal of Immunology, vol. 160, no. 6, pp. 3056-3059, 1998.

[37] Y. C. Q. Zang, S. Li, V. M. Rivera et al., "Increased CD8+ cytotoxic $\mathrm{T}$ cell responses to myelin basic protein in multiple sclerosis," Journal of Immunology, vol. 172, no. 8, pp. 5120-5127, 2004.

[38] D. M. W. Zaiss, C. P. J. Bekker, A. Gröne, B. A. Lie, and A. J. A. M. Sijts, "Proteasome immunosubunits protect against the development of CD8 T cell-mediated autoimmune diseases," Journal of Immunology, vol. 187, no. 5, pp. 2302-2309, 2011.

[39] J. D. Lünemann, N. Edwards, P. A. Muraro et al., "Increased frequency and broadened specificity of latent EBV nuclear antigen-1-specific T cells in multiple sclerosis," Brain, vol. 129, no. 6, pp. 1493-1506, 2006.

[40] S. Jilek, M. Schluep, P. Meylan et al., "Strong EBV-specific CD8+ T-cell response in patients with early multiple sclerosis," Brain, vol. 131, no. 7, pp. 1712-1721, 2008.

[41] P. Höllsberg, H. J. Hansen, and S. Haahr, "Altered CD8+ T cell responses to selected Epstein-Barr virus immunodominant epitopes in patients with multiple sclerosis," Clinical and Experimental Immunology, vol. 132, no. 1, pp. 137-143, 2003.

[42] S. Cepok, D. Zhou, R. Srivastava et al., "Identification of Epstein-Barr virus proteins as putative targets of the immune response in multiple sclerosis," Journal of Clinical Investigation, vol. 115, no. 5, pp. 1352-1360, 2005.

[43] J. Ishizuka, K. Grebe, E. Shenderov et al., "Quantitating T cell cross-reactivity for unrelated peptide antigens," Journal of Immunology, vol. 183, no. 7, pp. 4337-4345, 2009.

[44] N. Vigneron, V. Stroobant, J. Chapiro et al., "An antigenic peptide produced by peptide splicing in the proteasome," Science, vol. 304, no. 5670, pp. 587-590, 2004.

[45] A. Dalet, N. Vigneron, V. Stroobant, K.-I. Hanada, and B. J. Van Den Eynde, "Splicing of distant peptide fragments occurs in the proteasome by transpeptidation and produces the spliced antigenic peptide derived from fibroblast growth factor-5," Journal of Immunology, vol. 184, no. 6, pp. 3016-3024, 2010.

[46] J. Liepe, M. Mishto, K. Textoris-Taube et al., "The 20S proteasome splicing activity discovered by SpliceMet," PLoS Computational Biology, vol. 6, no. 6, Article ID e1000830, 2010.

[47] M. Mishto, A. Goede, K. T. Taube et al., "Driving forces of proteasome-catalyzed peptide splicing in yeast and humans," Molecular and Cellular Proteomics, vol. 11, no. 10, pp. 1008-1023, 2012.

[48] H.-G. Rammensee, "Protein surgery," Nature, vol. 427, no. 6971, pp. 203-204, 2004.

[49] K. Mori, M. Itoi, N. Tsukamoto, H. Kubo, and T. Amagai, "The perivascular space as a path of hematopoietic progenitor cells and mature T cells between the blood circulation and the thymic parenchyma," International Immunology, vol. 19, no. 6, pp. 745753, 2007.

[50] E. Bettelli, Y. Carrier, W. Gao et al., "Reciprocal developmental pathways for the generation of pathogenic effector TH17 and regulatory T cells," Nature, vol. 441, no. 7090, pp. 235-238, 2006.

[51] M. S. Maddur, P. Miossec, S. V. Kaveri, and J. Bayry, "Th17 cells: biology, pathogenesis of autoimmune and inflammatory diseases, and therapeutic strategies," The American Journal of Pathology, vol. 181, no. 1, pp. 8-18, 2012.

[52] J. S. Tzartos, M. A. Friese, M. J. Craner et al., "Interleukin-17 production in central nervous system-infiltrating $\mathrm{T}$ cells and glial cells is associated with active disease in multiple sclerosis," The American Journal of Pathology, vol. 172, no. 1, pp. 146-155, 2008.

[53] T. Carlson, M. Kroenke, P. Rao, T. E. Lane, and B. Segal, "The Th17-ELR+ CXC chemokine pathway is essential for the development of central nervous system autoimmune disease," Journal of Experimental Medicine, vol. 205, no. 4, pp. 811-823, 2008.

[54] V. Siffrin, H. Radbruch, R. Glumm et al., "In Vivo imaging of partially reversible Th17 cell-induced neuronal dysfunction in the course of encephalomyelitis," Immunity, vol. 33, no. 3, pp. 424-436, 2010.

[55] Y. Komiyama, S. Nakae, T. Matsuki et al., "IL-17 plays an important role in the development of experimental autoimmune encephalomyelitis," Journal of Immunology, vol. 177, no. 1, pp. 566-573, 2006.

[56] L. Cosmi, L. Maggi, V. Santarlasci et al., "Identification of a novel subset of human circulating memory CD4+ T cells that produce both IL-17A and IL-4," Journal of Allergy and Clinical Immunology, vol. 125, no. 1-3, pp. 222-30.e1-222-30.e4, 2010.

[57] K. Berer and G. Krishnamoorthy, "Commensal gut flora and brain autoimmunity: a love or hate affair?" Acta Neuropathologica, vol. 123, no. 5, pp. 639-651, 2012.

[58] J. Bienenstock and S. Collins, "99th Dahlem Conference on Infection, Inflammation and Chronic Inflammatory Disorders: psycho-neuroimmunology and the intestinal microbiota: clinical observations and basic mechanisms," Clinical and Experimental Immunology, vol. 160, no. 1, pp. 85-91, 2010.

[59] S. M. Collins, M. Surette, and P. Bercik, "The interplay between the intestinal microbiota and the brain," Nature Reviews Microbiology, vol. 10, no. 11, pp. 735-742, 2012.

[60] I. I. Ivanov, K. Atarashi, N. Manel et al., "Induction of intestinal Th17 cells by segmented filamentous bacteria," Cell, vol. 139, no. 3, pp. 485-498, 2009.

[61] C. O’Mahony, P. Scully, D. O’Mahony et al., “Commensalinduced regulatory $\mathrm{T}$ cells mediate protection against pathogenstimulated NF- $\kappa$ B activation," PLoS Pathogens, vol. 4, no. 8, Article ID e1000112, 2008.

[62] K. Atarashi, T. Tanoue, T. Shima et al., "Induction of colonic regulatory T cells by indigenous Clostridium species," Science, vol. 331, no. 6015, pp. 337-341, 2011.

[63] A. Jamshidian, V. Shaygannejad, A. Pourazar, S. H. ZarkeshEsfahani, and M. Gharagozloo, "Biased Treg/Th17 balance away from regulatory toward inflammatory phenotype in relapsed multiple sclerosis and its correlation with severity of symptoms," Journal of Neuroimmunology, vol. 262, no. 1-2, pp. 106-112, 2013.

[64] S. Lavasani, B. Dzhambazov, M. Nouri et al., "A novel probiotic mixture exerts a therapeutic effect on experimental autoimmune encephalomyelitis mediated by IL-10 producing 
regulatory T cells," PLoS ONE, vol. 5, no. 2, Article ID e9009, 2010.

[65] J. Ochoa-Repáraz, D. W. Mielcarz, L. E. Ditrio et al., "Role of gut commensal microflora in the development of experimental autoimmune encephalomyelitis," Journal of Immunology, vol. 183, no. 10, pp. 6041-6050, 2009.

[66] J. Ochoa-Repáraz, D. W. Mielcarz, Y. Wang et al., "A polysaccharide from the human commensal Bacteroides fragilis protects against CNS demyelinating disease," Mucosal Immunology, vol. 3, no. 5, pp. 487-495, 2010.

[67] Y. K. Lee, J. S. Menezes, Y. Umesaki, and S. K. Mazmanian, "Proinflammatory T-cell responses to gut microbiota promote experimental autoimmune encephalomyelitis," Proceedings of the National Academy of Sciences of the United States of America, vol. 108, supplement 1, pp. 4615-4622, 2011.

[68] K. Berer, M. Mues, M. Koutrolos et al., "Commensal microbiota and myelin autoantigen cooperate to trigger autoimmune demyelination," Nature, vol. 479, no. 7374, pp. 538-541, 2011.

[69] T. Muchamuel, M. Basler, M. A. Aujay et al., "A selective inhibitor of the immunoproteasome subunit LMP7 blocks cytokine production and attenuates progression of experimental arthritis," Nature Medicine, vol. 15, no. 7, pp. 781-787, 2009.

[70] K. W. Kalim, M. Basler, C. J. Kirk, and M. Groettrup, "Immunoproteasome subunit LMP7 deficiency and inhibition suppresses Th1 and Th17 but enhances regulatory T cell differentiation," Journal of Immunology, vol. 189, no. 8, pp. 4182-4193, 2012.

[71] W. Strober, I. Fuss, and P. Mannon, "The fundamental basis of inflammatory bowel disease," Journal of Clinical Investigation, vol. 117, no. 3, pp. 514-521, 2007.

[72] N. Schmidt, E. Gonzalez, A. Visekruna et al., "Targeting the proteasome: partial inhibition of the proteasome by bortezomib or deletion of the immunosubunit LMP7 attenuates experimental colitis," Gut, vol. 59, no. 7, pp. 896-906, 2010.

[73] M. Basler, M. Dajee, C. Moll, M. Groettrup, and C. J. Kirk, "Prevention of experimental colitis by a selective inhibitor of the immunoproteasome," Journal of Immunology, vol. 185, no. 1, pp. 634-641, 2010.

[74] S. Oh, C. Cudrici, T. Ito, and H. Rus, "B-cells and humoral immunity in multiple sclerosis. Implications for therapy," Immunologic Research, vol. 40, no. 3, pp. 224-234, 2008.

[75] P. Engel, J. A. Gómez-Puerta, M. Ramos-Casals, F. Lozano, and X. Bosch, "Therapeutic targeting of B cells for rheumatic autoimmune diseases," Pharmacological Reviews, vol. 63, no. 1, pp. 127-156, 2011.

[76] A. C. Chan, "B cell immunotherapy in autoimmunity: 2010 update," Molecular Immunology, vol. 48, no. 11, pp. 1344-1347, 2011.

[77] B. Serafini, B. Rosicarelli, R. Magliozzi, E. Stigliano, and F. Aloisi, "Detection of ectopic B-cell follicles with germinal centers in the meninges of patients with secondary progressive multiple sclerosis," Brain Pathology, vol. 14, no. 2, pp. 164-174, 2004.

[78] M. Duddy, M. Niino, F. Adatia et al., "Distinct effector cytokine profiles of memory and naive human B cell subsets and implication in multiple sclerosis," Journal of Immunology, vol. 178, no. 10, pp. 6092-6099, 2007.

[79] A. Bar-Or, L. Fawaz, B. Fan et al., "Abnormal B-cell cytokine responses a trigger of T-cell-mediated disease in MS?" Annals of Neurology, vol. 67, no. 4, pp. 452-461, 2010.

[80] K. Hawker, P. O'Connor, M. S. Freedman et al., "Rituximab in patients with primary progressive multiple sclerosis: results of a randomized double-blind placebo-controlled multicenter trial," Annals of Neurology, vol. 66, no. 4, pp. 460-471, 2009.

[81] S. L. Hauser, E. Waubant, D. L. Arnold et al., "B-cell depletion with rituximab in relapsing-remitting multiple sclerosis," The New England Journal of Medicine, vol. 358, no. 7, pp. 676-688, 2008.

[82] N. L. Monson, P. D. Cravens, E. M. Frohman, K. Hawker, and M. K. Racke, "Effect of rituximab on the peripheral blood and cerebrospinal fluid B cells in patients with primary progressive multiple sclerosis," Archives of Neurology, vol. 62, no. 2, pp. 258264, 2005.

[83] L. Kappos, D. Li, P. A. Calabresi et al., "Ocrelizumab in relapsing-remitting multiple sclerosis: a phase 2, randomised, placebo-controlled, multicentre trial," The Lancet, vol. 378, no. 9805, pp. 1779-1787, 2011.

[84] S. Lulu and E. Waubant, "Humoral-targeted immunotherapies in multiple sclerosis," Neurotherapeutics, vol.10, no. 1, pp. 34-43, 2013.

[85] S. E. Hensley, D. Zanker, B. P. Dolan et al., "Unexpected role for the immunoproteasome subunit LMP2 in antiviral humoral and innate immune responses," Journal of Immunology, vol. 184, no. 8, pp. 4115-4122, 2010.

[86] M. Maldonado, R. J. Kapphahn, M. R. Terluk et al., "Immunoproteasome deficiency modifies the alternative pathway of NFkappaB signaling," PLoS ONE, vol. 8, no. 2, Article ID e56187, 2013.

[87] M. W. Lin, D. Suan, K. Lenton et al., "Differentiating patterns of oligoclonal banding in the cerebrospinal fluid improves diagnostic utility for multiple sclerosis," Pathology, vol. 44, no. 3, pp. 248-250, 2012.

[88] O. Stich, S. Jarius, B. Kleer, C. Rasiah, R. Voltz, and S. Rauer, "Specific antibody index in cerebrospinal fluid from patients with central and peripheral paraneoplastic neurological syndromes," Journal of Neuroimmunology, vol. 183, no. 1-2, pp. 220 224, 2007.

[89] M. K. Storch, S. Piddlesden, M. Haltia, M. Iivanainen, P. Morgan, and H. Lassmann, "Multiple sclerosis: in situ evidence for antibody- and complement-mediated demyelination," Annals of Neurology, vol. 43, no. 4, pp. 465-471, 1998.

[90] I. Mayo, J. Arribas, P. Villoslada et al., "The proteasome is a major autoantigen in multiple sclerosis," Brain, vol. 125, no. 12, pp. 2658-2667, 2002.

[91] H. Thuy-Tien, M. Haugen, J. Aarseth, A. Storstein, and C. A. Vedeler, "Proteasome antibodies in patients with cancer or multiple sclerosis," Scandinavian Journal of Immunology, vol. 67, no. 4, pp. 400-403, 2008.

[92] N. H. Beyer, J. Milthers, B. A.-M. Lauridsen, G. Houen, and L. J. Frederiksen, "Autoantibodies to the proteasome in monosymptomatic optic neuritis may predict progression to multiple sclerosis," Scandinavian Journal of Clinical and Laboratory Investigation, vol. 67, no. 7, pp. 696-706, 2007.

[93] M. Brychcy, U. Kuckelkorn, G. Hausdorf et al., "Anti-20S proteasome autoantibodies inhibit proteasome stimulation by proteasome activator PA28," Arthritis and Rheumatism, vol. 54, no. 7, pp. 2175-2183, 2006.

[94] S. U. Sixt and B. Dahlmann, "Extracellular, circulating proteasomes and ubiquitin: incidence and relevance," Biochimica et Biophysica Acta, vol. 1782, no. 12, pp. 817-823, 2008.

[95] C. Jakob, K. Egerer, P. Liebisch et al., "Circulating proteasome levels are an independent prognostic factor for survival in multiple myeloma," Blood, vol. 109, no. 5, pp. 2100-2105, 2007. 
[96] O. Mueller, T. Anlasik, J. Wiedemann et al., "Circulating extracellular proteasome in the cerebrospinal fluid: a study on concentration and proteolytic activity," Journal of Molecular Neuroscience, vol. 46, no. 3, pp. 509-515, 2012.

[97] R. C. Lai, S. S. Tan, B. J. Teh et al., "Proteolytic potential of the MSC exosome proteome: implications for an exosomemediated delivery of therapeutic proteasome," International Journal of Proteomics, vol. 2012, Article ID 971907, 14 pages, 2012.

[98] G. A. Roth, B. Moser, C. Krenn et al., "Heightened levels of circulating $20 \mathrm{~S}$ proteasome in critically ill patients," European Journal of Clinical Investigation, vol. 35, no. 6, pp. 399-403, 2005.

[99] A. Minagar, W. Ma, X. Zhang et al., "Plasma ubiquitinproteasome system profile in patients with multiple sclerosis: correlation with clinical features, neuroimaging, and treatment with interferon-beta-1b," Journal of Neurology Research, vol. 34, no. 6, pp. 611-618, 2012.

[100] C. Stadelmann, C. Wegner, and W. Brück, "Inflammation, demyelination, and degeneration: recent insights from MS pathology," Biochimica et Biophysica Acta, vol. 1812, no. 2, pp. 275-282, 2011.

[101] R. E. Gonsette, "Neurodegeneration in multiple sclerosis: the role of oxidative stress and excitotoxicity," Journal of the Neurological Sciences, vol. 274, no. 1-2, pp. 48-53, 2008.

[102] H. Lassmann and J. van Horssen, "The molecular basis of neurodegeneration in multiple sclerosis," FEBS Letters, vol. 585, no. 23, pp. 3715-3723, 2011.

[103] L. Haider, M. T. Fischer, J. M. Frischer et al., "Oxidative damage in multiple sclerosis lesions," Brain, vol. 134, no. 7, pp. 1914-1924, 2011.

[104] S. M. Smerjac and O. A. Bizzozero, "Cytoskeletal protein carbonylation and degradation in experimental autoimmune encephalomyelitis," Journal of Neurochemistry, vol. 105, no. 3, pp. 763-772, 2008.

[105] J. Zheng and O. A. Bizzozero, "Accumulation of protein carbonyls within cerebellar astrocytes in murine experimental autoimmune encephalomyelitis," Journal of Neuroscience Research, vol. 88, no. 15, pp. 3376-3385, 2010.

[106] L. Papa and P. Rockwell, "Persistent mitochondrial dysfunction and oxidative stress hinder neuronal cell recovery from reversible proteasome inhibition," Apoptosis, vol. 13, no. 4, pp. 588-599, 2008.

[107] P. G. Sullivan, N. B. Dragicevic, J.-H. Deng et al., "Proteasome inhibition alters neural mitochondrial homeostasis and mitochondria turnover," Journal of Biological Chemistry, vol. 279, no. 20, pp. 20699-20707, 2004.

[108] C. T. Aiken, R. M. Kaake, X. Wang, and L. Huang, "Oxidative stress-mediated regulation of proteasome complexes," Molecular and Cellular Proteomics, vol. 10, no. 5, Article ID R110.006924, 2011.

[109] S. Grimm, A. Höhn, and T. Grune, "Oxidative protein damage and the proteasome," Amino acids, vol. 42, no. 1, pp. 23-38, 2012.

[110] T. Jung and T. Grune, "The proteasome and its role in the degradation of oxidized proteins," IUBMB Life, vol. 60, no. 11, pp. 743-752, 2008.

[111] T. Grune, K. Merker, G. Sandig, and K. J. A. Davies, "Selective degradation of oxidatively modified protein substrates by the proteasome," Biochemical and Biophysical Research Communications, vol. 305, no. 3, pp. 709-718, 2003.

[112] L. Farout and B. Friguet, "Proteasome function in aging and oxidative stress: implications in protein maintenance failure," Antioxidants and Redox Signaling, vol. 8, no. 1-2, pp. 205-216, 2006.
[113] T. Reinheckel, N. Sitte, O. Ullrich, U. Kuckelkorn, K. J. A. Davies, and T. Grune, "Comparative resistance of the $20 \mathrm{~S}$ and $26 \mathrm{~S}$ proteasome to oxidative stress," Biochemical Journal, vol. 335, no. 3, pp. 637-642, 1998.

[114] M. Kästle and T. Grune, "Proteins bearing oxidation-induced carbonyl groups are not preferentially ubiquitinated," Biochimie, vol. 93, no. 6, pp. 1076-1079, 2011.

[115] S. Kotamraju, S. Matalon, T. Matsunaga, T. Shang, J. M. Hickman-Davis, and B. Kalyanaraman, "Upregulation of immunoproteasomes by nitric oxide: potential antioxidative mechanism in endothelial cells," Free Radical Biology and Medicine, vol. 40, no. 6, pp. 1034-1044, 2006.

[116] A. M. Pickering, A. L. Koop, C. Y. Teoh, G. Ermak, T. Grune, and K. J. A. Davies, "The immunoproteasome, the $20 \mathrm{~S}$ proteasome and the PA28 $\alpha \beta$ proteasome regulator are oxidative-stressadaptive proteolytic complexes," Biochemical Journal, vol. 432, no. 3, pp. 585-594, 2010.

[117] A. M. Pickering and K. J. Davies, "Differential roles of proteasome and immunoproteasome regulators Pa28alphabeta, Pa28gamma and Pa200 in the degradation of oxidized proteins," Archives of Biochemistry and Biophysics, vol. 523, no. 2, pp. 181190, 2012.

[118] Q. Ding, S. Martin, E. Dimayuga, A. J. Bruce-Keller, and J. N. Keller, "LMP2 knock-out mice have reduced proteasome activities and increased levels of oxidatively damaged proteins," Antioxidants and Redox Signaling, vol. 8, no. 1-2, pp. 130-135, 2006.

[119] D. Bates, "Treatment effects of immunomodulatory therapies at different stages of multiple sclerosis in short-term trials," Neurology, vol. 76, supplement 1, no. 1, pp. S14-S25, 2011.

[120] C. F. Lucchinetti, J. Parisi, and W. Bruck, "The pathology of multiple sclerosis," Neurologic Clinics, vol. 23, no. 1, pp. 77-105, 2005.

[121] G. Frisullo, D. Plantone, A. Marti et al., "Type 1 immune response in progressive multiple sclerosis," Journal of Neuroimmunology, vol. 249, no. 1-2, pp. 112-116, 2012.

[122] E. Bellavista, F. Andreoli, M. Parenti et al., "Immunoproteasome in cancer and neuropathologies: a new therapeutic target?" Current Pharmaceutical Design, vol. 19, no. 4, pp. 702-718, 2013.

[123] A. Perchellet, I. Stromnes, J. M. Pang, and J. Goverman, "CD8+ $\mathrm{T}$ cells maintain tolerance to myelin basis protein by 'epitope theft"' Nature Immunology, vol. 5, no. 6, pp. 606-614, 2004.

[124] M. A. Friese, K. B. Jakobsen, L. Friis et al., "Opposing effects of HLA class I molecules in tuning autoreactive CD8 + T cells in multiple sclerosis," Nature Medicine, vol. 14, no. 11, pp. 12271235,2008

[125] Human Microbiome Project Consortium, "Structure, function and diversity of the healthy human microbiome," Nature, vol. 486, no. 7402, pp. 207-214, 2012.

[126] M. Candela, E. Biagi, S. Maccaferri, S. Turroni, and P. Brigidi, "Intestinal microbiota is a plastic factor responding to environmental changes," Trends in Microbiology, vol. 20, no. 8, pp. 385391, 2012.

[127] A. Perchellet, T. Brabb, and J. M. Goverman, "Crosspresentation by nonhematopoietic and direct presentation by hematopoietic cells induce central tolerance to myelin basic protein," Proceedings of the National Academy of Sciences of the United States of America, vol. 105, no. 37, pp. 14040-14045, 2008. 


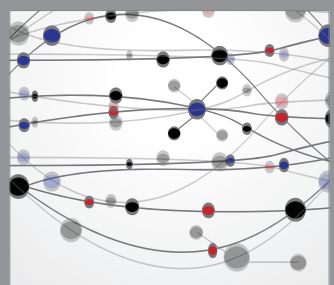

The Scientific World Journal
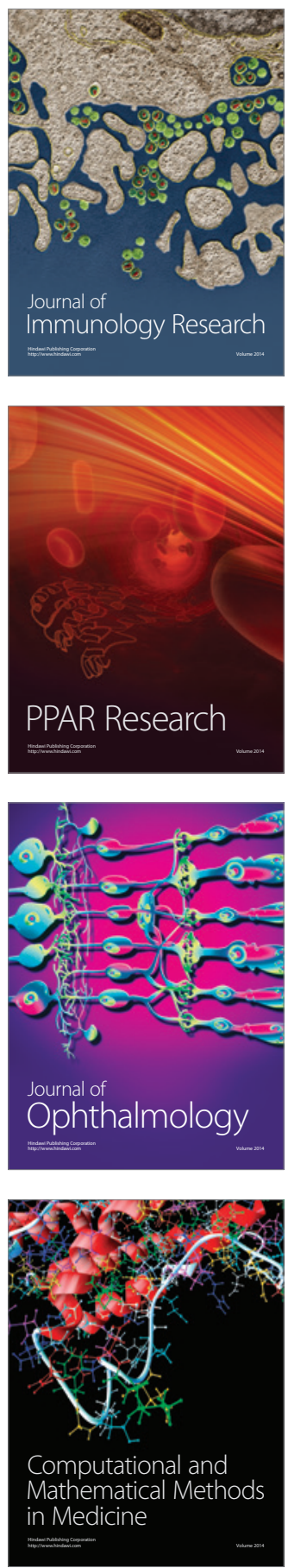

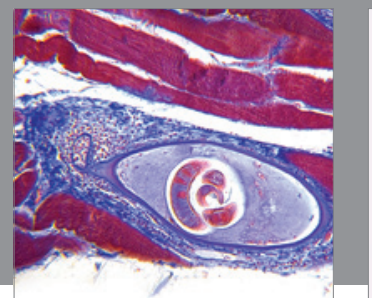

Gastroenterology

Research and Practice
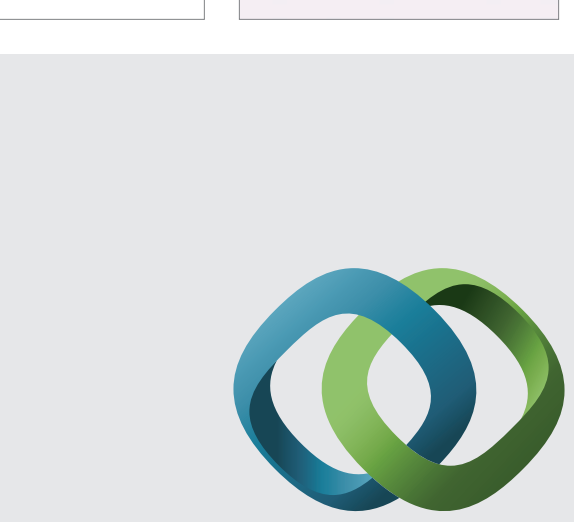

\section{Hindawi}

Submit your manuscripts at

http://www.hindawi.com
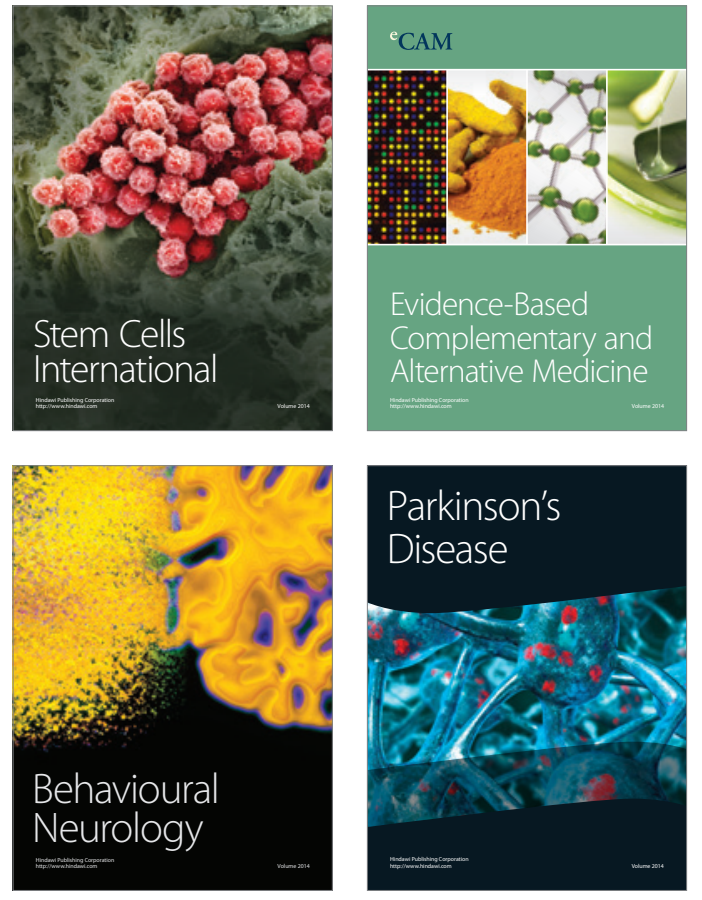
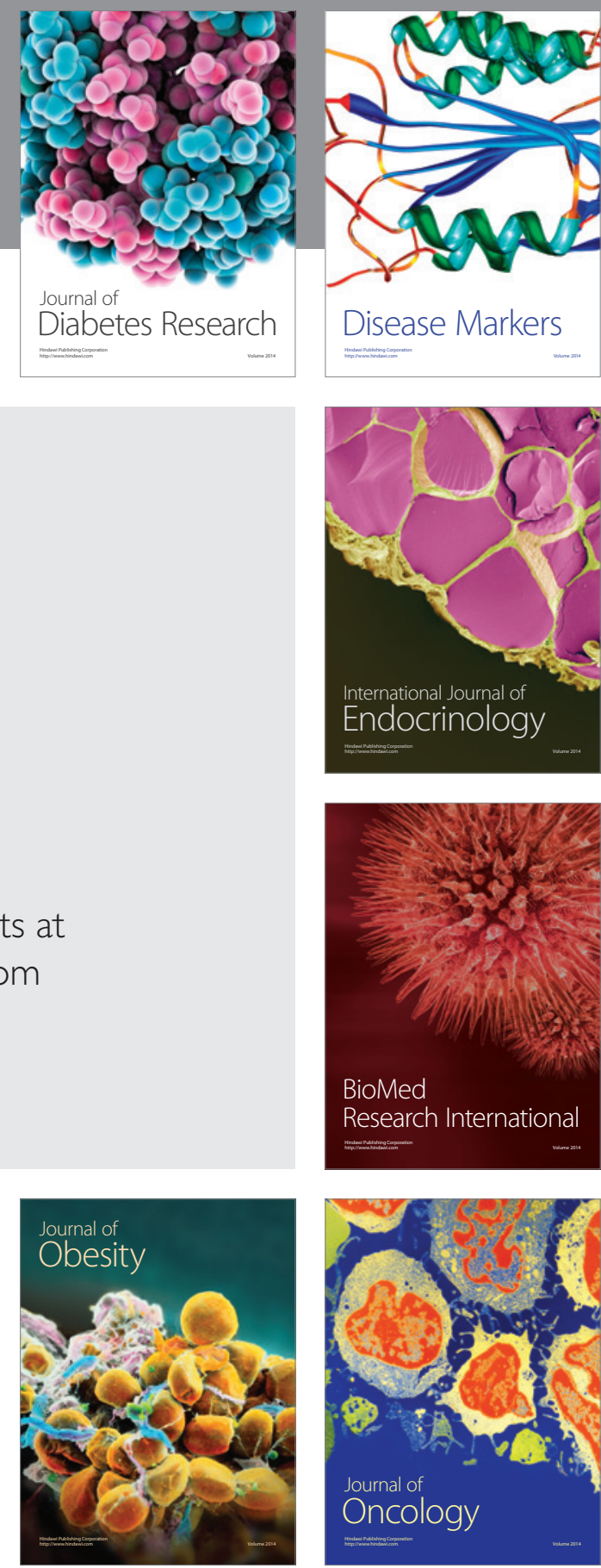

Disease Markers
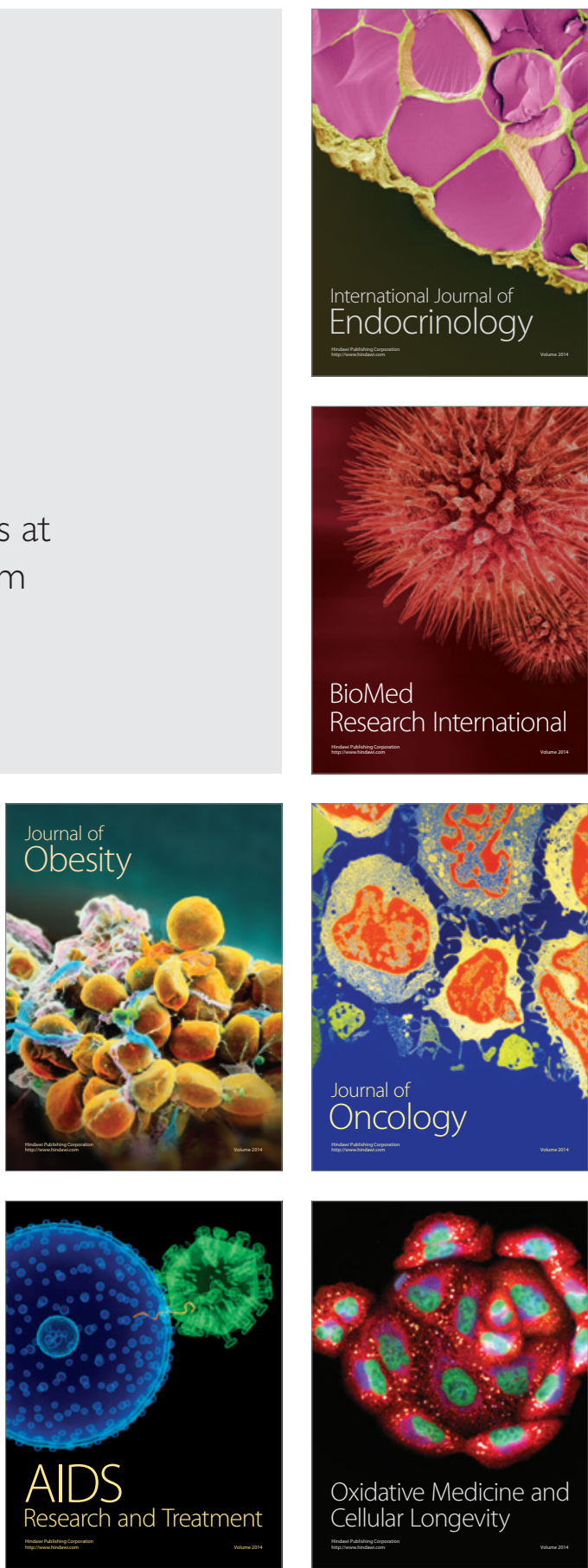